\title{
Tribocorrosão de Juntas Soldadas Similares e Dissimilares Utilizando um Aço Martensítico e um Aço SAE 1010: um Estudo Preliminar
}

\author{
Cintia Cristiane Petry Mazzaferro ${ }^{1}$ (D) André Marubin Fich², Thalita Cristina de Paula ${ }^{1}$, Daniela Fátima Giarollo ${ }^{1}$, \\ José Antônio Esmerio Mazzaferro ${ }^{1}$ \\ ${ }^{1}$ Universidade Federal do Rio Grande do Sul, Departamento de Engenharia Mecânica, Laboratório de Soldagem \& Técnicas Conexas, Porto Alegre, RS, Brasil \\ ${ }^{2}$ FALCONI Consultores de Resultados, Porto Alegre, RS, Brasil
}

Como citar: Mazzaferro CCP, Fich AM, Paula TC, Giarollo DF, Mazzaferro JAE. Tribocorrosão de juntas soldadas similares e dissimilares utilizando um aço martensítico e um aço SAE 1010: um estudo preliminar. Soldagem \& Inspeção. 2020;25:e2506. https://doi.org/10.1590/0104-9224/SI25.06

\begin{abstract}
Resumo: A interação entre desgaste e corrosão, ou seja, a tribocorrosão, ocorre em diversas aplicações industriais e biomédicas e pode levar a uma degradação acentuada do material. O objetivo do presente trabalho foi comparar a resistência ao desgaste em meio aquoso de juntas similares de um aço martensítico (Hardox 500), e de juntas dissimilares entre o aço Hardox e um aço SAE 1010. As juntas foram obtidas empregando-se o processo de soldagem arco submerso, com energia de soldagem de $7,7 \mathrm{~kJ} / \mathrm{cm}$. Ensaios de microdesgaste por deslizamento linear recíproco foram realizados na presença de água artificial $(0,05 \mathrm{M} \mathrm{NaCl})$, em amostras de dois conjuntos soldados, um de materiais similares e outro de materiais dissimilares. As regiões ensaiadas foram os metais de solda (MS) e as zonas afetadas pelo calor (ZAC), estas últimas nas sub-regiões que apresentavam o menor valor de dureza, em cada conjunto. Para comparação, também foram ensaiados os metais-base (MB) do aço SAE 1010 e do aço Hardox. Como as chapas de aço Hardox possuíam um revestimento de silicato de zinco, condição na qual o aço era fornecido, para este aço os ensaios de corrosão-desgaste foram efetuados em amostras com o revestimento, e também sem ele. Dentre todas as condições estudadas, a maior resistência em tribocorrosão foi verificada para o aço Hardox com o revestimento. Das amostras ensaiadas sem revestimento, a degradação ocasionada pela tribocorrosão foi menor no MB do aço Hardox. Nos demais casos, foi observada a corrosão intensificada pelo desgaste, principalmente para o MB do SAE 1010, onde houve a dissolução acentuada do material adjacente à borda da trilha, fora da região de desgaste.
\end{abstract}

Palavras-chave: Desgaste; Corrosão; Tribocorrosão; Aço martensítico; SAE 1010.

\section{Tribocorrosion of Similar and Dissimilar Welded Joints Using a Martensitic Steel and a SAE 1010 Steel: a Preliminary Study}

\begin{abstract}
Tribocorrosion is the interaction between wear and corrosion, which occur in several industrial and biomedical applications, resulting in a pronounced degradation of the material. The aim of this work was to compare the wear resistance in aqueous solution of similar joints of a martensitic (Hardox 500) steel, and of dissimilar joints between the steels Hardox and SAE 1010. The joints were carried out using submerged arc welding, with an energy input of $7.7 \mathrm{~kJ} / \mathrm{cm}$. Reciprocating sliding microwear tests were performed in a solution of $0.05 \mathrm{M} \mathrm{NaCl}$, in samples of similar and dissimilar joints. The regions analyzed in tribocorrosion were weld metals (WM) and heat affected zones (HAZ), these in the sub-regions which exhibited the lowest hardness value, in each welded joint. For comparison, tests in base materials (BM) of SAE 1010 and Hardox steels were also performed - in Hardox steels, in samples with and without a coating of zinc silicate. Among all tested conditions, the higher tribocorrosion resistance was observed for the coated Hardox. In the group of samples which were tested without any coating, degradation caused by tribocorrosion process was less significative in the BM of Hardox steel. In the other studied conditions, it was observed wear enhanced corrosion, mainly for the BM of SAE 1010 steel in which occurred an intense dissolution of the material in the area adjacent to the wear track, outside the track.
\end{abstract}

Key-words: Wear; Corrosion; Tribocorrosion; Martensitic steel; SAE 1010. 


\section{Introdução}

A ocorrência simultânea de desgaste e corrosão existe em vários sistemas: na agroindústria, indústrias de óleo e gás, de mineração, metal-mecânica e também em aplicações biomédicas. De acordo com a norma ASTM G40-13, 2013 [1], tribocorrosão é um processo que leva a uma transformação irreversível do material resultante de interações eletroquímicas, químicas e mecânicas simultâneas que ocorrem devido a um contato tribológico.

Mathew et al. [2] afirmam que a tribocorrosão é caracterizada pelo sinergismo entre corrosão e desgaste, e resulta em degradação do material, que por sua vez é geralmente maior do que poderia se esperar pela simples soma da degradação dos processos individuais. Ainda segundo esses autores, um sistema em tribocorrosão pode ser afetado por solicitações mecânicas, por condições eletroquímicas na superfície do metal em desgaste, por propriedades da solução em contato e/ou pelos materiais em contato e suas propriedades de superfície. Desta forma, o comportamento em tribocorrosão de um material pode ser afetado, entre outros fatores, pela sua composição química e microestrutura, meio, cargas, velocidades, tipo de contato e tipo de desgaste envolvidos [3-9].

O comportamento em tribocorrosão de metais passivos, ou de metais que possuem tratamentos de superfície/recobrimentos, é diferente daquele de metais ativos, como os aços ao carbono. No entanto, estes últimos são utilizados em várias aplicações que envolvem tribocorrosão devido às suas características de boa relação entre resistência mecânica e peso, aliado a um custo usualmente menor quando comparado a metais passivos [4]. Diversos estudos que tratam sobre a tribocorrosão de aços ao carbono têm sido realizados. Utilizando ensaios de deslizamento linear recíproco em um aço de alta resistência e baixa liga, López-Ortega et al. [4,10] observaram que o deslizamento no meio aquoso (água do mar artificial) acelerou a corrosão da área fora do desgaste, e que ele foi maior quando a temperatura de ensaio foi elevada de 2 oC para $23{ }^{\circ} \mathrm{C}$, devido ao aumento da corrosão do aço. Resultados similares em relação ao aumento da temperatura foram reportados por Jiang et al. [11], que mostraram que o teor de oxigênio dissolvido também influenciou na tribocorrosão de um aço carbono de alta dureza submetido a ensaios do tipo erosão-corrosão utilizando uma lama preparada com 35\% de areia de sílica em uma solução de 3,5\% de $\mathrm{NaCl}$. Ensaios de erosão-corrosão também foram realizados por Islam e Farhat [12], utilizando um aço API X-70 em um meio de $\mathrm{CO} 2$ e 0,03M de $\mathrm{NaCl}$ com partículas de óxido de alumínio. Esses autores observaram que o comportamento do aço foi afetado pelas modificações na superfície do material, relacionadas à camada encruada formada na superfície desgastada e oxidação desta, devido ao processo simultâneo de desgaste e corrosão. Efetuando ensaios de deslizamento na presença de $\mathrm{CO} 2$ e $3,0 \%$ de $\mathrm{NaCl}$, o efeito da microestrutura do aço, martensítica ou ferrítico-perlítica, foi avaliado por Trausmuth et al. [13]. Eles verificaram que a camada de óxido formada na martensita era mais densa, o que favoreceu o menor desgaste comparado à outra microestrutura. Enquanto isso, Liu et al. [14] mostraram que a corrosão de um aço estrutural em água do mar reduziu o seu desgaste, ao contrário do que acontecia quando os ensaios de desgaste do tipo pino-sobre-disco eram realizados em água destilada, e atribuíram o fato à maior corrosão localizada do aço nesse último meio. Além disso, os autores constataram que em água do mar a superfície gerada na região de corrosão-desgaste era mais dura do que a do material inicial, evitando o seu desgaste. Por fim, em um estudo recente Hacısalihoğlu et al. [15] concluíram que o tratamento de nitretação aumentou a resistência à corrosão e ao desgaste de três diferentes tipos de aços Hardox, por alterar o mecanismo de corrosão, de generalizada para corrosão por pites.

No entanto, a literatura ainda é escassa no que diz respeito ao comportamento em tribocorrosão de juntas de aço ao carbono soldadas. Desta forma, o presente trabalho tem como objetivo verificar o comportamento em tribocorrosão de juntas similares e dissimilares entre os aços Hardox 500 e SAE 1010, analisando a resposta dos metais-base, metais de solda e zonas afetadas pelo calor (sub-região de menor dureza em cada junta) em ensaios de microdesgaste por deslizamento linear recíproco na presença de água artificial.

\section{Matérias e Métodos}

\subsection{Materiais utilizados e procedimento de soldagem}

Os materiais utilizados para a produção das juntas soldadas foram chapas de aproximadamente $200 \times 100 \mathrm{~mm}$ e espessura de 6,1 mm, tanto do aço Hardox 500, que possuía microestrutura martensítica e dureza de 489,4 $\pm 6,4$ HV, como também do aço SAE 1010, que apresentava microestrutura composta predominantemente por ferrita, com pequena quantidade de perlita, como pode ser observado na Figura 1, e dureza de 127,33 $\pm 6,12$ HV. A composição química dos aços é mostrada na Tabela 1. Salienta-se que as chapas de Hardox 500 possuíam uma camada de revestimento (primer) inorgânico à base de silicato de zinco, que de acordo com o fabricante SSAB e a literatura [16-18], além de auxiliar na proteção à corrosão das chapas, é quimicamente inerte, possui elevada adesão ao substrato, elevada dureza e resistência à abrasão. A espessura do revestimento era de $23,9 \pm 4,3 \mu \mathrm{m}$, sendo esse valor uma média de vinte medições realizadas em imagens obtidas em microscópio ótico Zeiss Axio Lab.A1, com auxílio do programa de edição de imagens ImageJ. O valor de rugosidade do revestimento Sa era 7,99 \pm 0,56 $\mu$ m, determinado utilizando um interferômetro a laser Brucker Contour-GT, no Laboratório de Análises Multiusuários da Universidade Federal do Rio Grande do Sul (LAMAS - UFRGS), e é resultante da média de quatro regiões analisadas em amostras do aço revestido. Na literatura é citado que o revestimento de silicato de zinco possui elevada dureza, porém não foi possível 
encontrar um valor de referência relacionado a ele (em alguma escala que pudesse ser convertida para Vickers) e os autores do presente trabalho tampouco conseguiram determinar a dureza em amostras de aço revestidas com ele, devido à sua baixa espessura e elevada rugosidade.

Foram produzidas duas juntas soldadas: uma delas, denominada de junta similar, empregava duas chapas de aço Hardox 500, e a outra junta utilizava chapas dissimilares, ou seja, uma do aço Hardox 500 e outra do aço SAE 1010. Em seguida, as faces laterais e a região superior e inferior das chapas, no local onde ocorreria a soldagem, foram lixadas para a retirada de possíveis óxidos e do revestimento das chapas de Hardox 500, com o objetivo de inibir a possível influência destes na junta soldada.

O processo de soldagem empregado foi o arco submerso, onde as chapas foram encostadas nas laterais de maior dimensão, sem deixar nenhum espaçamento entre elas, que possuíam chanfro reto. Além disso, utilizaram-se os consumíveis fluxo Carboox neutro ME, secado durante uma hora e trinta minutos a uma temperatura de 250 o $\mathrm{C}$ e resfriado no interior do forno, e o arame AWS EL-12, com diâmetro de 2,38 mm.

Os parâmetros de soldagem empregados visaram garantir a penetração total da solda e foram selecionados com base no trabalho desenvolvido utilizando aços com a mesma espessura [19]. Foi utilizado velocidade de soldagem de $10,83 \mathrm{~mm} / \mathrm{s}$, corrente contínua de $380 \mathrm{~A}$ e tensão elétrica de $22 \mathrm{~V}$, gerando uma energia de soldagem de aproximadamente $7,7 \mathrm{~kJ} / \mathrm{cm}$.
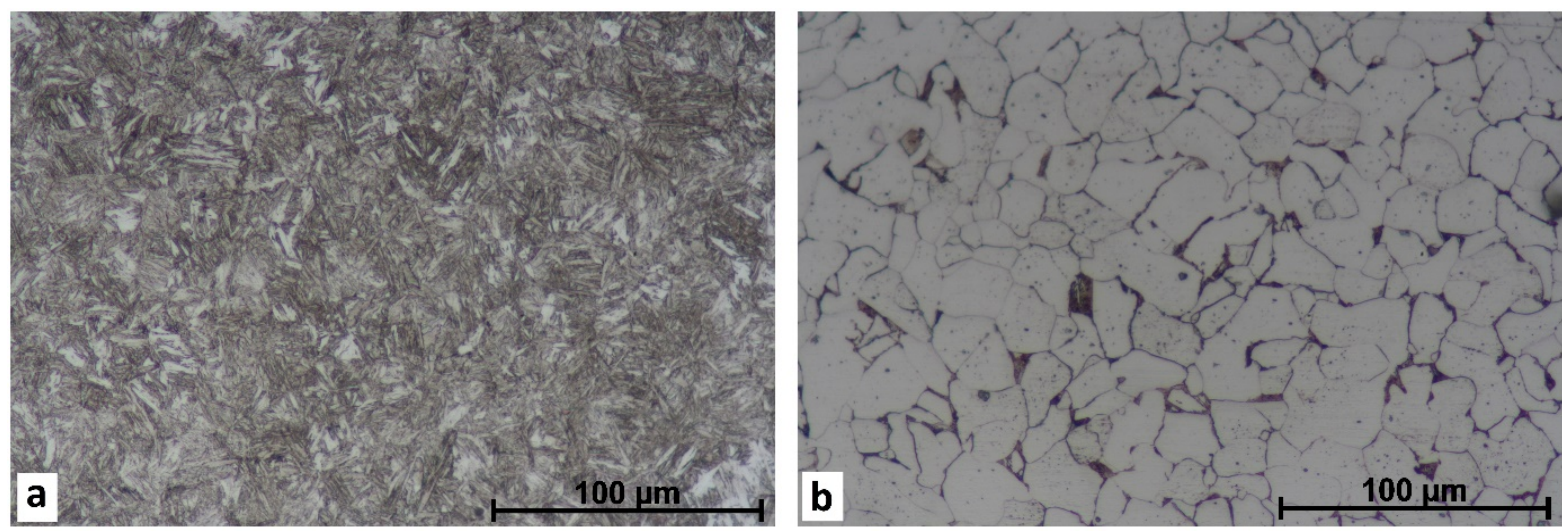

Figura 1. Microestruturas dos aços utilizados para a produção das juntas soldadas: (a) aço Hardox 500, (b) aço SAE 1010.

Tabela 1. Composição química dos aços utilizados (\% em peso).

\begin{tabular}{ccccccccccc}
\hline & C & Mn & Si & Al & P & S & Cr & Ni & Mo & B \\
Hardox 500 & 0,26 & 0,70 & 0,25 & 0,050 & 0,008 & $<0,001$ & 0,60 & 0,008 & 0,02 & 0,0012 \\
SAE 1010 & 0,11 & 0,46 & 0,015 & 0,041 & 0,009 & 0,006 & - & - & - & - \\
\hline
\end{tabular}

\subsection{Caracterizações das juntas soldadas}

Amostras para análises macro- e micrográficas foram cortadas no sentido transversal ao cordão de solda, e suas superfícies foram preparadas seguindo procedimento padrão de preparação metalográfica, e após atacadas quimicamente com Nital 10\%, e observadas em lupa Leica EZ e em microscópio ótico Zeiss Axio Lab.A1. Estas mesmas amostras foram utilizadas para obter os perfis de microdurezas, cujas medições foram efetuadas em um microdurômetro Insize, a $1 \mathrm{~mm}$ da superfície superior das chapas, aplicando uma carga de $500 \mathrm{~g}$ durante $10 \mathrm{~s}$, com distância entre indentações de 0,5 mm.

\subsection{Ensaios de tribocorrosão}

Para os ensaios de tribocorrosão, as superfícies das amostras na face da solda foram fresadas e lixadas até a lixa \#1200, o que resultou em uma rugosidade Sa de 0,18 \pm 0,04 $\mu \mathrm{m}$ (média das análises em quatro regiões diferentes de uma amostra lixada). Esses ensaios foram realizados no Laboratório de Pesquisa em Corrosão da Universidade Federal do Rio Grande do Sul (LAPEC - UFRGS), utilizando um Tribômetro UMT (Universal Micro Tribometer) da marca CETR - Test Equipment Tribology. Entretanto, foi acoplado ao tribômetro um potenciostato EG\&G Princeton Applied Research (PAR) Modelo 273 com o intuito de medir o potencial de circuito aberto (OCP), ou seja, a resposta do sistema à corrosão. Segundo Landolt [20] o OCP é criado pela imersão em eletrólito de um metal, o qual sofre reações de dissolução com formação de íons na solução e permanência dos elétrons dentro do metal; estes elétrons polarizam o metal gerando um campo elétrico dentro da solução que faz com que os íons fiquem retidos na vizinhança da interface metal-eletrólito, formando uma dupla camada elétrica e gerando uma diferença de potencial entre o metal e a solução, conhecida como potencial de eletrodo. 
O sistema para a aquisição dos dados de OCP conta com dois eletrodos: o primeiro, conforme já mencionado, é a própria amostra (Eletrodo de Trabalho - ET), o qual é fixado na parte inferior da célula, e o segundo é o eletrodo de referência (Eletrodo de Calomelano Saturado - ECS), este acoplado na parte lateral próxima a amostra, ambos conectados ao PAR. O meio corrosivo, ou seja, o eletrólito utilizado, foi $\mathrm{NaCl}$ 0,05 M (água "artificial"). Empregou-se o desgaste por deslizamento linear recíproco, do tipo esfera-sobre-plano, utilizando uma esfera de alumina $\left(\mathrm{Al}_{2} \mathrm{O}_{3}\right)$, com diâmetro de 4,762 mm, dureza de $1463 \pm 41 \mathrm{HV}$, coeficiente de Poisson $v$ e módulo de elasticidade $E$ iguais a 0,21 e $300 \mathrm{GPa}$, respectivamente [21]. Os ensaios foram realizados nos metais-base (MB), nos metais de solda (MS) e nas regiões das zonas afetadas pelo calor (ZAC) que apresentavam a menor dureza, em ambas juntas soldadas, sendo a área exposta ao fluido de $177 \mathrm{~mm}^{2}$.

A Figura 2a apresenta uma visão geral dos componentes do sistema para os ensaios de tribocorrosão, e a Figura $2 b$ exibe, de forma esquemática, o sistema de uma célula utilizada nesses ensaios. Os parâmetros utilizados nos ensaios são exibidos na Tabela 2, e na Tabela 3 estão listadas as condições de contato iniciais entre os metais-base e a esfera, considerando a teoria de Hertz.
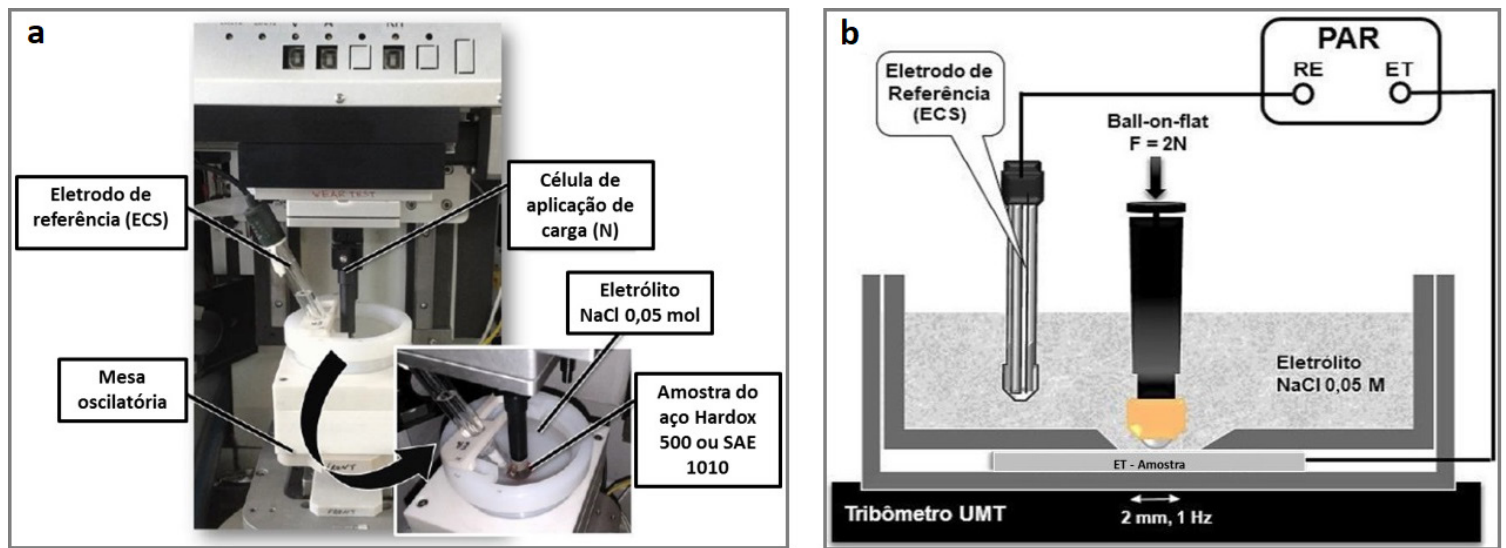

Figura 2. (a) Visão geral do tribômetro UMT adaptado para ensaios em tribocorrosão. (b) Sistema esquematizado de uma célula utilizada nos ensaios (adaptado de Ramos et al. [22]).

Tabela 2. Parâmetros utilizados nos ensaios de tribocorrosão.

\begin{tabular}{cc}
\hline Força normal aplicada & $\mathbf{2 N}$ \\
Frequência & $1 \mathrm{~Hz}$ \\
Tempo de desgaste & $3 \mathrm{~h}$ \\
Comprimento de desgaste & $2 \mathrm{~mm}$ \\
Eletrólito & $\mathrm{NaCl} 0,05 \mathrm{M}$ \\
Temperatura & $22 \pm 5$ ㅇ C \\
Eletrodo de referência & $\mathrm{ECS}$ \\
\hline
\end{tabular}

Tabela 3. Tensões de contato entre esfera e metais-base.

\begin{tabular}{ccc}
\hline & Aço Hardox & Aço SAE 1010 \\
Coeficiente de Poisson & $0,30[23]$ & $0,29[24]$ \\
Módulo de elasticidade, GPa & $210[23]$ & $190[24]$ \\
Diâmetro de contato, mm & 0,060 & 0,061 \\
Pressão de contato média, MPa & 710,1 & 680,9 \\
Máxima pressão de contato, MPa & 1065,1 & 1021,5 \\
Máxima tensão cisalhante, MPa & 330,2 & 319,0 \\
Profundidade de máxima tensão cisalhante, $\mathrm{mm}$ & 0,014 & 0,015 \\
\hline
\end{tabular}

Utilizando como base o trabalho de Azzi et al. [25], as peças foram imersas no eletrólito e mediu-se o OCP durante 1.800 segundos (30 minutos). Então, iniciou-se o desgaste e, além do $\mathrm{OCP}$, monitorou-se o coeficiente de atrito durante 10.800 segundos ( 3 horas). Após cessar o desgaste, durante 3.600 segundos (1 hora), continuou-se a registrar o OCP dos materiais. Essa sequência pode ser observada de forma esquemática na Figura 3. 


\subsection{Cálculos dos volumes desgastados}

As regiões contendo as trilhas desgastadas das amostras foram analisadas em um interferômetro a laser Brucker Contour-GT, no LAMAS - UFRGS. Com os dados adquiridos no interferômetro foram obtidas as topografias das trilhas desgastadas. Em cada trilha foram feitas oito seções (transversais a ela), evitando-se as bordas das trilhas onde havia a inversão de direção do movimento da esfera. Cada seção representava um perfil 2D da trilha, então em cada seção foi calculada a área abaixo da linha que representava a superfície da amostra. Essa área indicava o material desgastado (em 2D), e o volume desgastado em cada condição foi calculado a partir da área média calculada nas oito seções da trilha, multiplicando-se pelo comprimento da trilha, que era de $2 \mathrm{~mm}$.

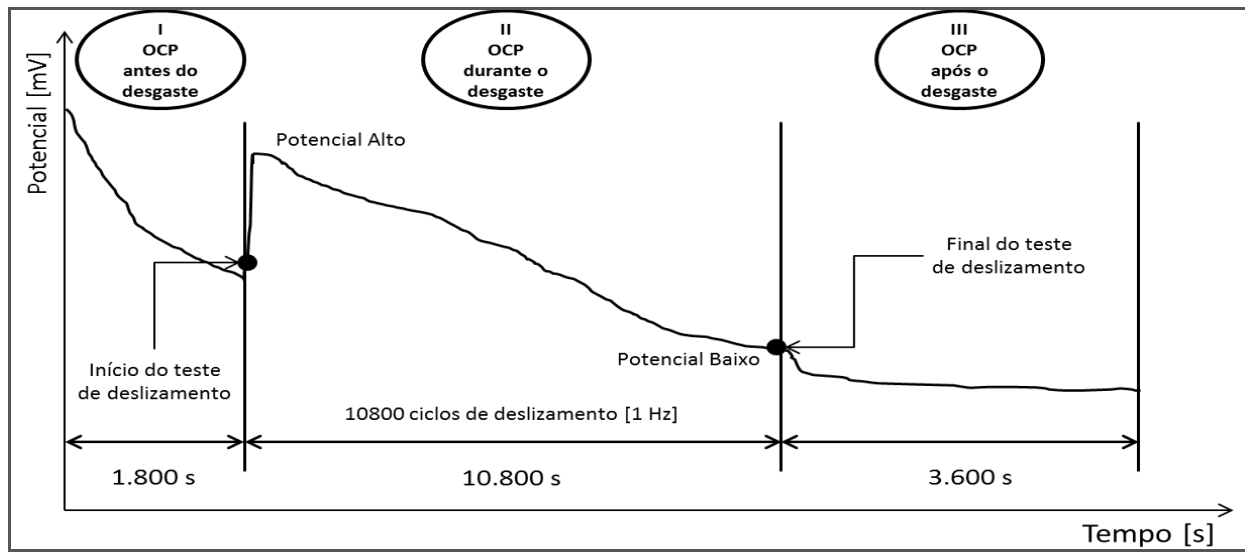

Figura 3. Sequência de operações durante o teste de tribocorrosão ilustrada pela evolução do potencial de circuito aberto (OCP) (adaptado de Azzi et al. [25]).

Também foram calculados os volumes desgastados das esferas de alumina usadas como contra-corpo nos ensaios. Através das imagens realizadas em microscópio ótico das suas regiões desgastadas, com o auxílio de um programa de edição de imagens (ImageJ), para cada condição ensaiada foi calculada a área desgastada da esfera (média de quatro medições), que foi aproximada à de um círculo de mesma área para o cálculo do diâmetro e por fim, com esse valor, foi calculado o volume desgastado, como é sugerido pela norma ASTM G133-2005 [26].

\section{Resultados e Discussão}

A Figura 4 mostra as macrografias das duas juntas produzidas, a similar (usando duas chapas de aço Hardox 500), e a dissimilar (empregando uma chapa de aço Hardox 500 e outra de aço SAE 1010). Os valores das diluições foram de $45 \%$ e de $43 \%$ para a junta similar e dissimilar, respectivamente. Devido às diluições, às composições químicas do eletrodo e dos metais-base, às microestruturas dos metais-base, e também aos ciclos térmicos, houve uma variação dos valores de dureza ao longo das juntas soldadas mostrada na Figura 5. Na junta similar, Figura 5a, a dureza média do MS foi de aproximadamente $220 \mathrm{HV}$, valor que também foi observado na região de menor dureza da ZAC. Na região adjacente ao MS, correspondente à ZAC de grãos grosseiros, a dureza média atinge o valor próximo de $300 \mathrm{HV}$, havendo uma queda até a região subcrítica da ZAC, a mais afastada do MS. Na junta dissimilar, Figura 5b, foi observado esse mesmo comportamento do perfil de microdurezas no lado da chapa de Hardox 500, apesar dos valores diferentes no MS devido à contribuição do aço SAE 1010 na sua composição química, o que posteriormente afetou a microestrutura resultante após a solidificação e resfriamento, enquanto que no lado da chapa aço SAE 1010, a dureza decresceu continuamente desde o MS até atingir o MB. Observou-se, ainda, que a extensão da ZAC no aço Hardox 500 foi bem maior do que no aço SAE 1010, devido à maior sensibilidade da sua microestrutura inicial (martensita revenida) ao ciclo térmico.
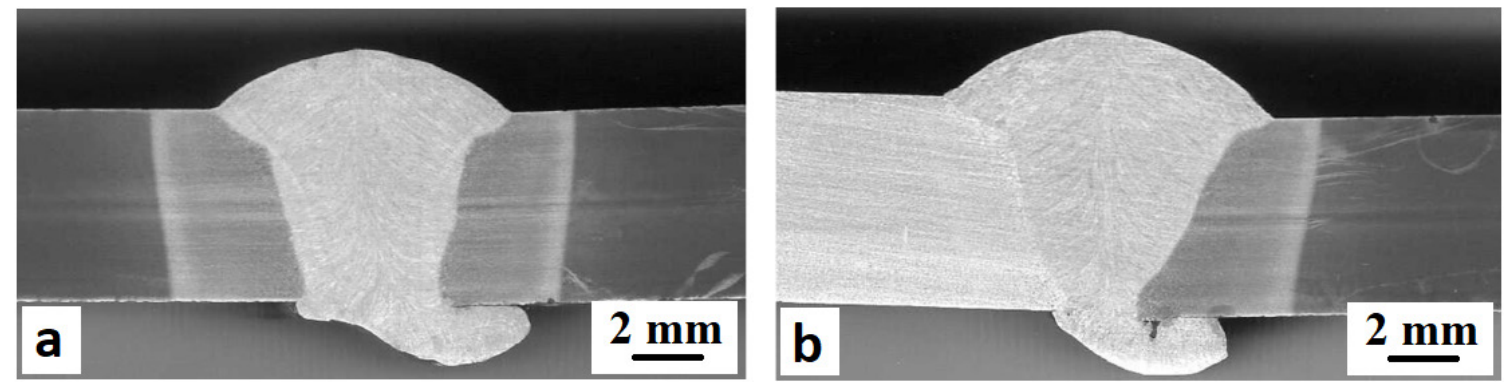

Figura 4. Macrografias das juntas produzidas: (a) similar; (b) dissimilar. 
As análises das microestruturas resultantes vêm de encontro com as observações relativas aos perfis de durezas. No MS da junta similar, Figura 6a, a microestrutura era composta por ferrita acicular (FA), ferrita de contorno de grão (FG) e ferrita de segunda fase alinhada (FSA), enquanto que no MS dissimilar estavam presentes, além da ferrita de contorno de grão, ferrita de segunda fase não alinhada (FSN) e alinhada (FSA), como pode ser observado na Figura 6b. Ferrita (F) e perlita degenerada (PD) eram as fases presentes na microestrutura da ZAC de menor valor de dureza da junta dissimilar, observada na chapa de aço SAE 1010, mostrada na Figura 6d. Alterações microestruturais significativas foram observadas na ZAC de menor valor de dureza da junta similar, correspondente ao aço Hardox 500, Figura 6c: devido ao ciclo de temperaturas imposto pelo processo de soldagem, houve um severo revenimento da martensita do metal-base, o que levou à formação/coalescimento de carbonetos, que em algumas regiões se apresentavam em bandas. Além disso, também em bandas foi observada a presença de pequenos grãos equiaxiais de ferrita, indicando a exposição da região a temperatura intercrítica durante a soldagem - possivelmente essa região localizava-se na interface entre a ZAC subcrítica e a ZAC intercrítica.
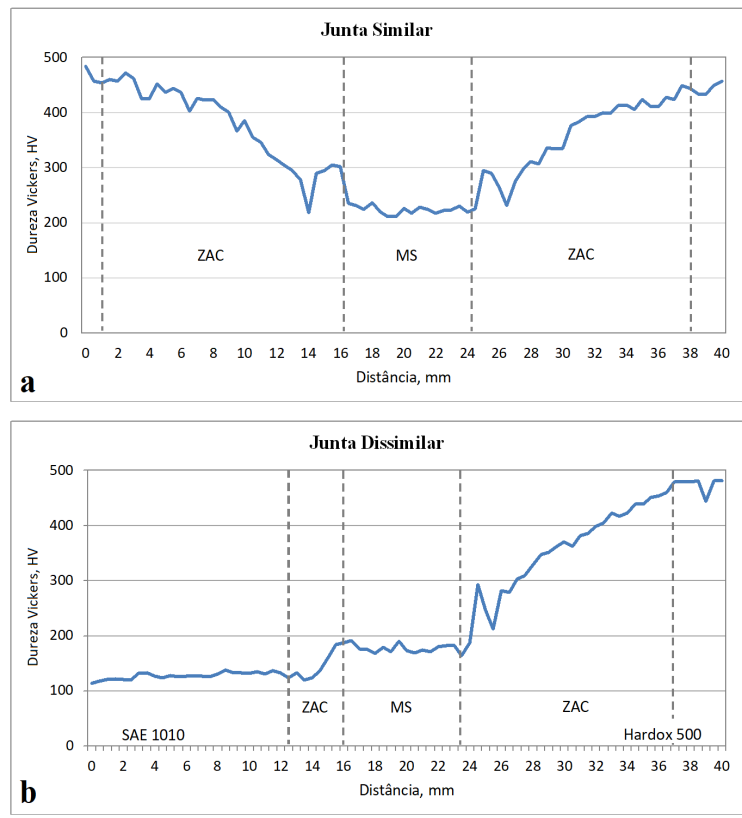

Figura 5. Perfis de microdurezas das juntas, realizados a $1 \mathrm{~mm}$ das superfícies das chapas: (a) similar; (b) dissimilar.
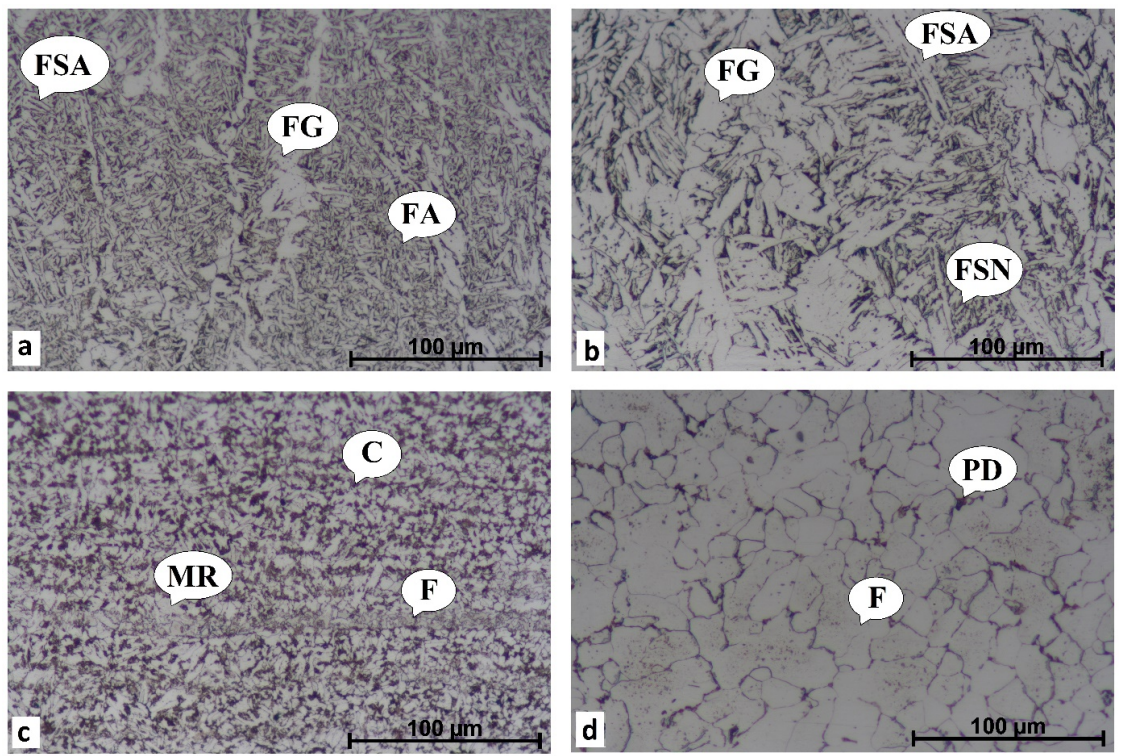

Figura 6. Microestruturas de regiões das juntas soldadas: metal de solda da junta (a) similar e (b) dissimilar; zona afetada pelo calor de menor dureza da junta (c) similar (na chapa do aço Hardox) e (d) dissimilar (na chapa do aço SAE 1010). FSA=ferrita de segunda fase; $\mathrm{FG}=$ ferrita de contorno de grão; $\mathrm{FA}=$ ferrita acicular; $\mathrm{FSN}=$ ferrita de segunda fase não alinhada; $\mathrm{C}=$ carbonetos; $\mathrm{MR}=$ martensita auto-revenida; $\mathrm{F}=$ ferrita; $\mathrm{PD}=$ perlita degenerada. 
Os resultados dos ensaios de tribocorrosão são mostrados na Figura 7. Em todas as condições estudadas, exceto no MB do aço Hardox com revestimento (primer), percebeu-se que no período em que as amostras ficaram em contato com a solução aquosa, ainda sem o deslizamento da esfera (1800 s iniciais), houve uma diminuição do potencial de circuito aberto (OCP), indicando o início do processo de corrosão nas superfícies dos materiais. No MB com revestimento, percebeu-se uma pequena flutuação nos valores do OCP nesse período inicial, provavelmente devido à natureza desse revestimento, à base de silicato de zinco, que tem a função de proteger o substrato contra a corrosão. É importante salientar que os valores de OCP representam as características eletroquímicas não apenas na região de desgaste, mas em toda a região que está em contato com o eletrólito.
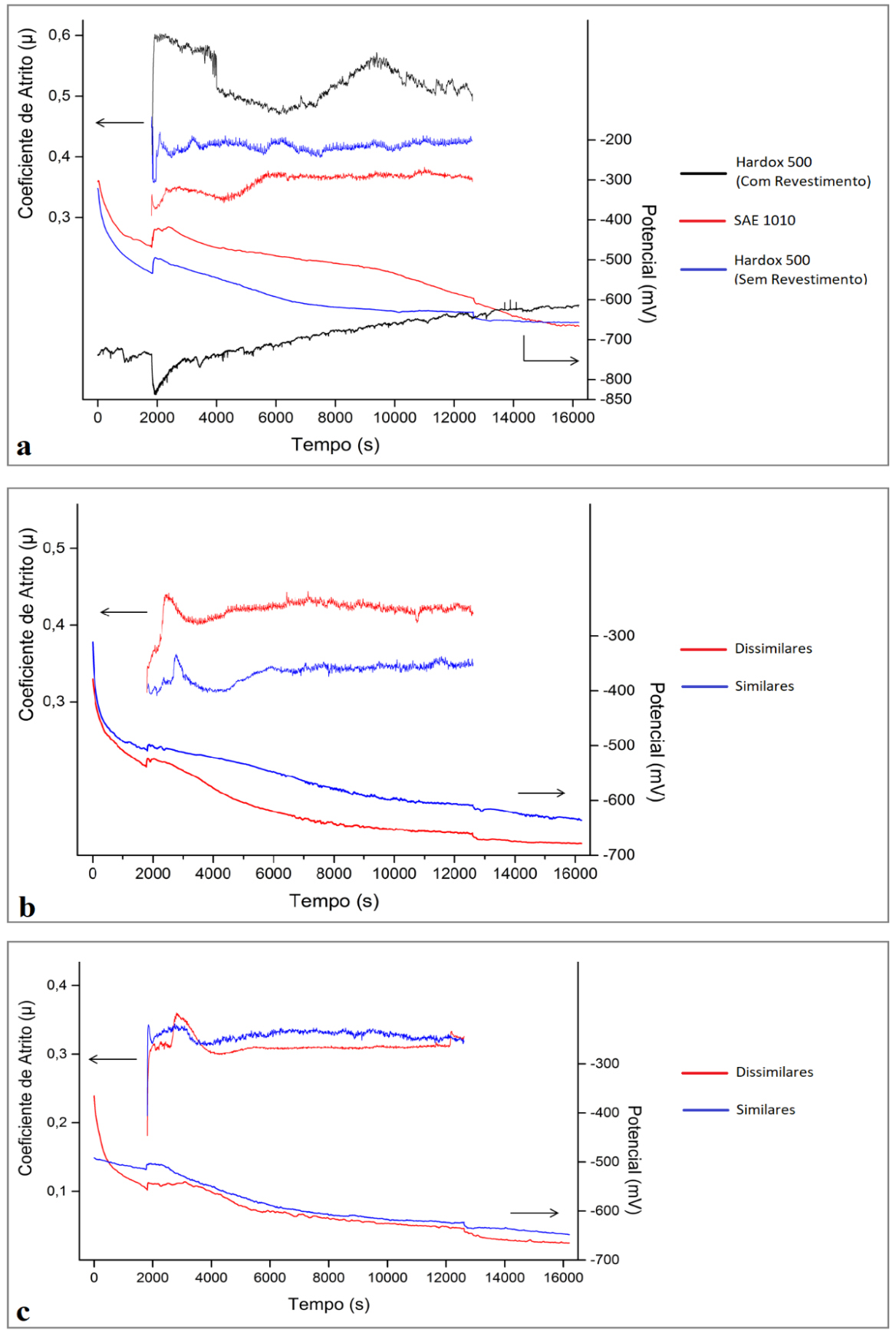

Figura 7. Variações dos potenciais de circuito aberto e dos coeficientes de atrito durante os ensaios de tribocorrosão; (a) metais-base; (b) metais de solda; (c) zonas afetadas pelo calor de menor dureza.

No MB (aço Hardox) com revestimento, assim que o deslizamento da esfera de alumina iniciou, foi observada uma diminuição brusca no valor do OCP medido, que se presume estar associado à destruição de parte da camada do revestimento, expondo uma nova área ao eletrólito. No entanto, para essa condição houve o aumento gradual do valor do OCP durante todo o período de desgaste, indicando a proteção contra a corrosão através do revestimento. Ao final da etapa de desgaste, o valor 
de OCP permaneceu praticamente constante. Por outro lado, no que diz respeito ao coeficiente de atrito (CoF) para esse material, o valor médio de CoF foi de 0,52 . Houve elevada flutuação nos valores de CoF durante o desgaste, e eles foram sempre maiores do que os observados nas demais condições estudadas, como mostrado na Figura 7. As flutuações e os valores mais elevados de CoF em relação aos outros materiais podem estar associados às interações entre as asperezas da esfera e do material, que possuía valor de rugosidade alta, o que fez com que a área de contato entre as asperezas dos dois aumentasse. Devido à elevada rugosidade do revestimento, parte dos debris formados pode ter ficado alojada nos 'vales' da superfície do revestimento, na região de desgaste, e parte pode ter sido retirada da região pelo auxílio do movimento da solução, além de também poder ficar acumulada nas bordas da trilha. Deve-se considerar, também, o desgaste sofrido pela esfera nesse ensaio em questão, que foi sensivelmente maior do que nas demais condições ensaiadas, como mostra a Tabela 4, onde podem ser observados os volumes removidos nas regiões que sofreram desgaste (trilhas) e nas esferas de alumina, após os ensaios de cada condição estudada. Nas demais condições em estudo, o início do deslizamento da esfera alterou as condições eletroquímicas nas áreas onde ela fazia contato, e provocou um pequeno aumento nos valores de OCP. Nesse estágio inicial de desgaste, em todas as condições foi possível observar uma pequena região na qual o OCP manteve-se constante, mas logo após houve uma queda no seu valor. Com exceção do MB do aço SAE 1010, em todas as condições estudadas (de amostras sem revestimento) o OCP diminuiu gradualmente até estabilizar, e ficou constante até o encerramento do deslizamento. Como pode ser observado na Figura 7c, as taxas de variação de OCP, assim como seus próprios valores, foram muito similares nos ensaios efetuados nas ZAC de menor dureza das duas juntas soldadas, mesmo tratando-se de microestruturas e durezas bem distintas. Porém, o comportamento do MB do aço SAE 1010 foi diferente; além de seus valores de OCP serem maiores do que os dos demais materiais, a queda do seu potencial foi praticamente constante durante toda a etapa de deslizamento da esfera. Os valores médios dos CoF nas duas ZAC e no MS da junta similar foram próximos, de cerca de 0,33 , assim como os valores médios do MB do aço Hardox sem revestimento e do MS da junta dissimilar, que foram de 0,42. No MB do aço SAE 1010, o valor médio foi intermediário entre os das outras condições ensaiadas, ficando em 0,37. No MB do aço Hardox durante todo o período de desgaste foi observada uma pequena flutuação nos valores de CoF, enquanto no MB do aço SAE 1010 houve uma diminuição no valor de CoF, seguida de aumento e estabilização. Para os metais de solda e ZAC de menor dureza, os CoF durante a etapa de deslizamento da esfera de alumina apresentaram uma maior variação no período inicial de deslizamento, exibindo um pico aproximadamente 20 min após o início de desgaste com posterior queda e leve aumento seguido de relativa estabilização em valores menores do que aquele de pico apresentado anteriormente. López et al. [10] citam que o aumento no coeficiente de atrito na etapa inicial de desgaste em ensaios de tribocorrosão pode ser atribuído à remoção dos óxidos formados no período onde as amostras estavam em contato com a solução, sem deslizamento, alterando a natureza e morfologia da área de contato entre a esfera e as amostras. Após essa etapa inicial, a queda nos valores de CoF com os seus posteriores aumentos podem estar associados às interações entre esfera-materiais relacionadas ao desgaste, que poderiam causar deformação plástica e encruamento, e à corrosão, como a formação de produtos de corrosão e sua possível remoção ou compactação na trilha quando ocorre o deslocamento da esfera, como citado por Murkute et al. [27] e Noh e Jang [28]. Essas interações podem explicar, por exemplo, a diferença nos valores de CoF médio entre o MB do aço SAE 1010 e a ZAC dissimilar, de 0,37 e 0,33, respectivamente: da mesma forma que foi observado por Wu et al. [29], que analisou o desgaste de aços em soluções de água e água do mar artificiais, é possível que os produtos de corrosão gerados na trilha de desgaste da ZAC dissimilar tenham ficado nessa região de contato com a esfera e contribuído para a lubrificação do sistema.

Tabela 4. Volumes desgastados nas trilhas e nas esferas de alumina, $\mathrm{mm}^{3} \times 10^{-5}$.

\begin{tabular}{ccc}
\hline & Trilha & Esfera \\
MB - Hardox 500 com revestimento & NA* & $130,00 \pm 3,36$ \\
MB - Hardox 500 sem revestimento & $0,71 \pm 0,04$ & $0,68 \pm 0,03$ \\
MB - SAE 1010 & $23,5 \pm 9,01$ & $5,99 \pm 0,17$ \\
MS - Similar & $2,20 \pm 0,81$ & $6,12 \pm 0,38$ \\
MS - Dissimilar & $1,81 \pm 0,39$ & $1,65 \pm 0,09$ \\
ZAC - Similar & $2,62 \pm 0,46$ & $6,31 \pm 0,16$ \\
ZAC - Dissimilar & $3,47 \pm 0,14$ & $1,82 \pm 0,10$ \\
\hline${ }^{*}$ NA=ñ̃o
\end{tabular}

*NA=não aplicável: houve desgaste apenas do revestimento, que era muito heterogêneo, não sendo possível calcular o volume desgastado.

Na última etapa dos ensaios, na qual as amostras ainda ficavam em contato com o eletrólito durante $3600 \mathrm{~s}$, mas sem o deslizamento, observou-se uma queda adicional nos valores de OCP (exceto para o MB com revestimento, como já havia sido mencionado). Após essa última etapa, o MB do aço SAE 1010 e a ZAC de menor valor de dureza da junta dissimilar, localizada na chapa do aço SAE 1010, atingiram o mesmo OCP, praticamente o mesmo valor exibido pelo MB do aço Hardox sem revestimento. $\mathrm{O}$ valor menos negativo de OCP foi exibido pelo $\mathrm{MB}$ do aço Hardox com revestimento, e o segundo menos negativo foi o do MS da junta similar. 
Imagens das trilhas de desgaste e das esferas em algumas condições de ensaio são mostradas na Figura 8. O revestimento do aço Hardox possuía elevada rugosidade, e a esfera não chegou a atingir o MB durante o ensaio, como é mostrado na Figura 8a. $O$ desgaste da esfera foi bastante acentuado nessa condição, e as bordas adjacentes à sua região desgastada ficaram com debris aderidos (partículas removidas da trilha, pelo desgaste). Para essa condição, como foi mostrado na Tabela 4, não foi possível calcular o volume removido na região de desgaste, devido à heterogeneidade na rugosidade do revestimento.

Observando-se as imagens das trilhas mostradas na Figura 8, e também perfis de seções transversais às trilhas na Figura 9 , é possível notar que, com exceção da amostra de Hardox com revestimento, as bordas das trilhas apresentavam material com altura maior do que a superfície das chapas dos aços, o que poderia estar associado à deformação plástica durante o processo de desgaste-corrosão e/ou acúmulo de produto de corrosão nas bordas das trilhas. Fez-se uma análise aproximada das tensões de contato nas regiões/condições estudadas, envolvendo também o cálculo da carga necessária para o início do escoamento, de acordo com a Equação 1 [30].

$\mathrm{p}_{\mathrm{c}}=\frac{(\pi \mathrm{K})^{3}}{6}\left(\frac{\mathrm{H}}{\mathrm{E}}\right)^{2} \mathrm{HR}^{2}$

Onde $H$ é a dureza do material, GPa, $E$ é o módulo de elasticidade combinado entre esfera e plano, $R$ é o raio da esfera, mm, e $K$ é o fator de máxima pressão de contato, função do coeficiente de Poisson $v$ do material. No presente trabalho, $K$ foi calculado através da Equação 2 [31]:

$\mathrm{K}=0,4645+0,314 v+0,1943 v^{2}$

Nota-se que essas Equações levam em consideração a dureza do material ao invés da tensão de escoamento, assim como o coeficiente de Poisson, para o cálculo da carga crítica, de acordo com abordagens apresentadas nos trabalhos de Lin e Lin [31] e Pintaude [32], este último mostrando que há diferenças quando a dureza ou a tensão de escoamento é considerada em contatos.

Os resultados obtidos estão mostrados na Tabela 5. Para os MS e ZAC das juntas similares, os mesmos valores do módulo de elasticidade e coeficiente de Poisson do aço Hardox 500 foram utilizados, enquanto para os MS e ZAC das juntas dissimilares foram usados os dados do SAE 1010. Desta forma, os valores de raio de contato, pressões de contato média e máxima, tensão cisalhante máxima e sua profundidade no material são os mesmos (já mostrados na Tabela 3). Porém, como os valores de dureza nas diferentes regiões eram distintos, as cargas necessárias para início da deformação plástica diferem entre si, como se pode observar na Tabela 5. Note que o cálculo não foi efetuado para o revestimento (primer), devido à indisponibilidade das suas propriedades mecânicas (coeficiente de Poisson, módulo de elasticidade e dureza). No entanto, de uma forma simplificada, se forem analisados os dados referentes ao MB do aço Hardox 500, na Tabela 3, a máxima tensão cisalhante estaria localizada a uma profundidade de $0,014 \mathrm{~mm}$, que por sua vez é menor do que a espessura do revestimento (igual a 0,024 mm), ou seja, ela estaria localizada no revestimento. Mesmo que houvesse a possibilidade de alguma deformação plástica do revestimento, a Figura 8a mostra que a esfera não atingiu o metal-base.

Tabela 5. Cargas necessárias para o escoamento, para cada condição estudada.

\begin{tabular}{ccccccc}
\hline & MB - Hardox $\mathbf{5 0 0}$ & MB - SAE $\mathbf{1 0 1 0}$ & MS - Similar & MS - Dissimilar & ZAC - Similar & ZAC - Dissimilar \\
Dureza, GPa & 4,80 & 1,25 & 2,16 & 1,72 & 2,26 & 1,23 \\
$\begin{array}{c}\text { Carga necessária } \\
\text { para escoamento, } \mathrm{N}\end{array}$ & 35,14 & 0,57 & 3,18 & 1,93 & 3,63 & 0,57 \\
\hline
\end{tabular}

Os resultados da Tabela 5 mostram que, por essa análise, a força aplicada nos ensaios de tribocorrosão, que era de $2 \mathrm{~N}$, foi suficiente para causar a deformação plástica no metal-base do aço SAE 1010, no MS da solda dissimilar e na região de menor dureza da ZAC dissimilar. Como a carga calculada para o início do escoamento do MS da junta similar era maior do que a utilizada nos ensaios, é provável que o material observado nas bordas da trilha dessa condição, Figuras 8d e 9c, que poderia ser material deformado plasticamente, possa estar relacionado ao acúmulo de produto de corrosão nas bordas da trilha. Nessas análises que abordam a mecânica do contato, é importante salientar que como o desgaste ocorria na presença de solução, a exposição dos materiais à solução gerava produtos de corrosão (óxidos), e esses óxidos também deveriam ser levados em consideração para os cálculos - para tanto, seria necessário analisar os tipos de óxidos formados e utilizar as suas propriedades mecânicas, para recalcular as tensões de contato e cargas para início do escoamento. Isso não foi feito no presente trabalho. 

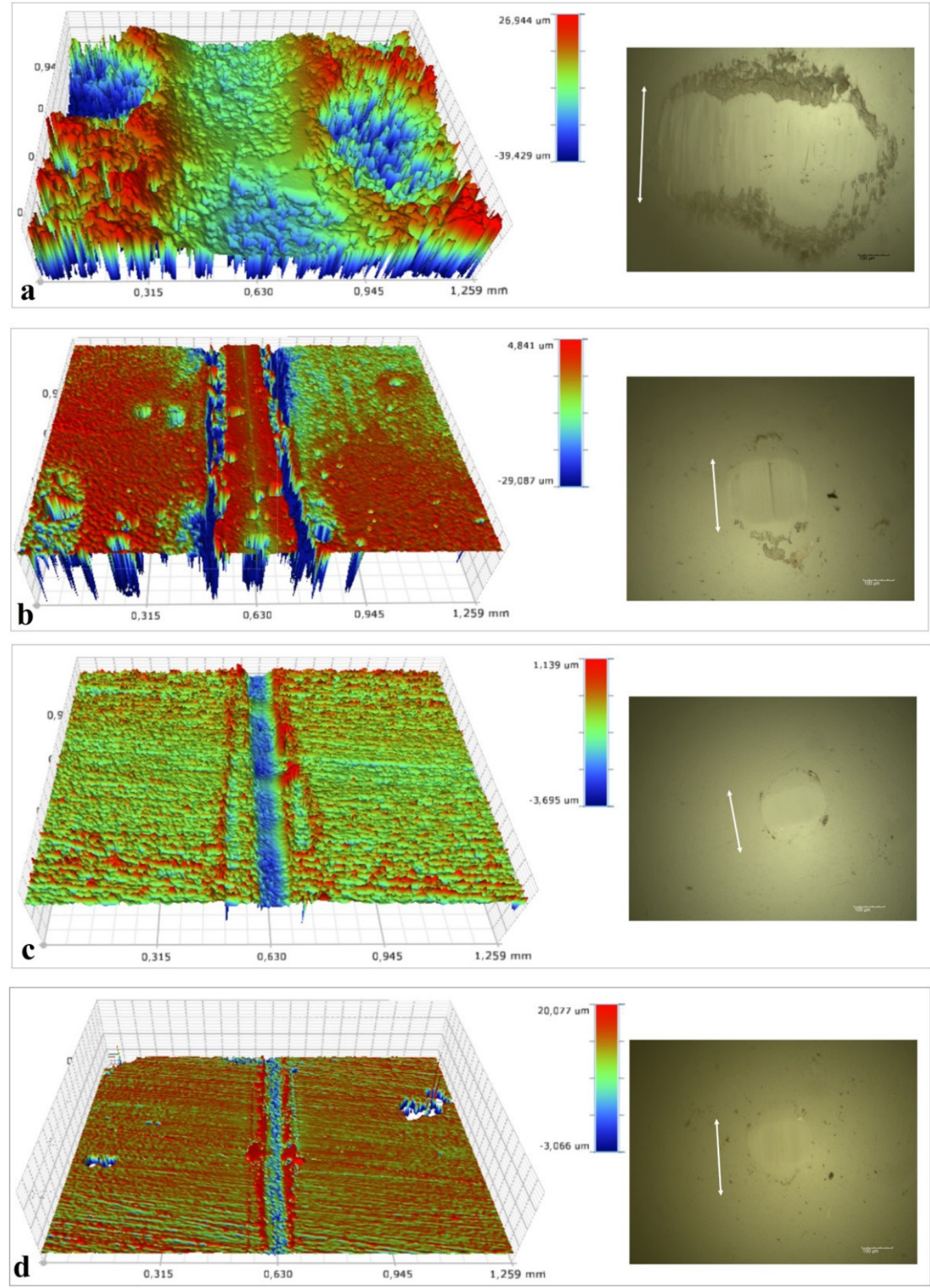

Figura 8. Imagens centrais às trilhas desgastadas e das esferas de alumina: (a) MB do aço Hardox com revestimento; (b) MB do aço SAE 1010; (c) ZAC de menor valor de dureza da junta dissimilar; (d) MS da junta similar. Nas imagens das esferas, as setas mostram as direções de deslizamento.

O MB do aço SAE 1010 teve o maior volume removido nos ensaios de tribocorrosão. As tensões de contato entre a esfera e o aço em questão (Tabela 3) devem ter causado a deformação plástica do material, o que está de acordo com os resultados da Tabela 5. Essa deformação pode também ter contribuído para o encruamento do material, o que o torna mais resistente à deformação. Aliado a isso, houve a formação de óxidos e a interação da esfera com eles. Um exemplo dessa interação pode ser observado na Figura 8b, onde aproximadamente no centro da trilha há um sulco, que provavelmente é resultante de debris que ficaram entre a superfície da esfera de alumina e a região de desgaste, e que atuaram ativamente no desgaste abrasivo nesse local. 

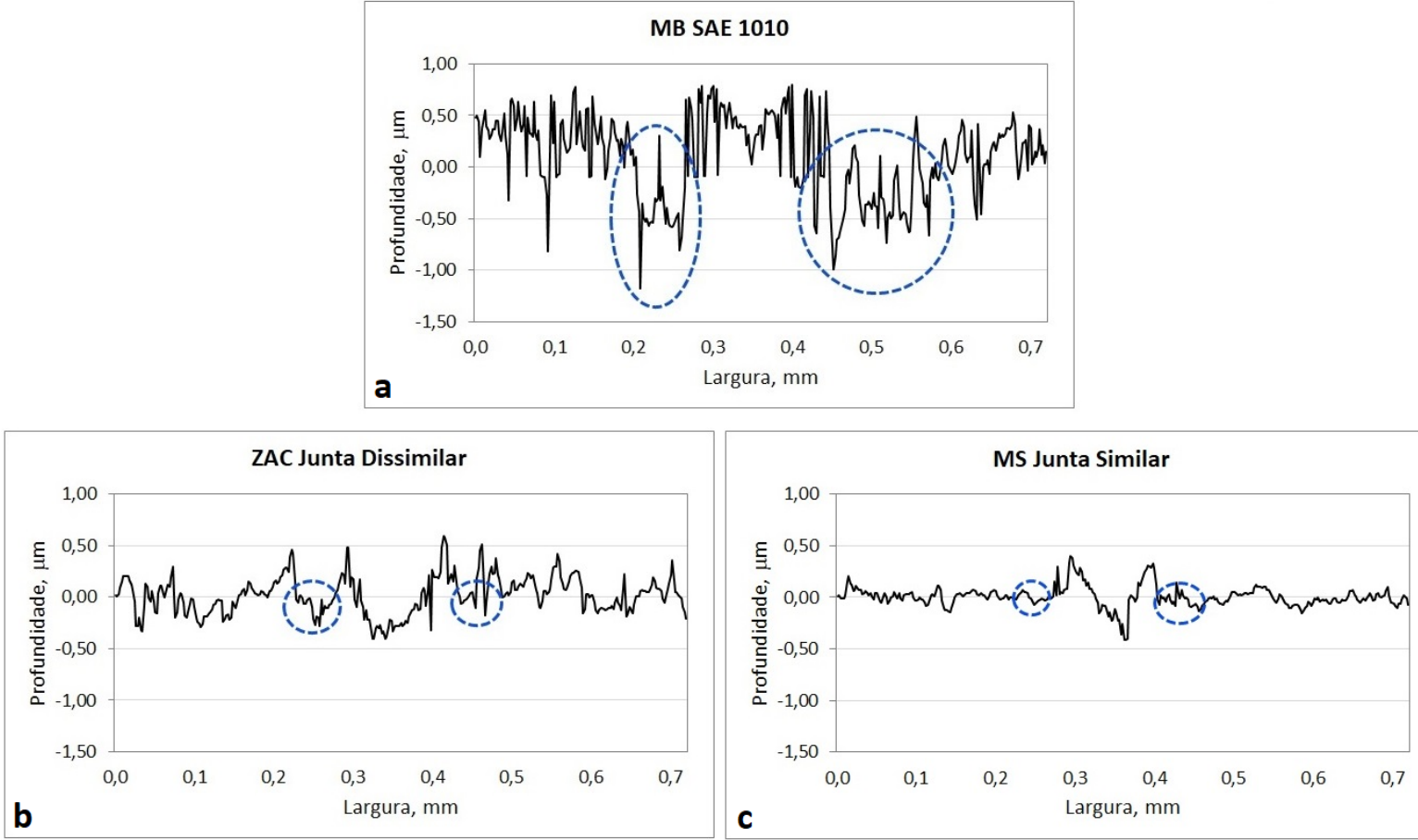

Figura 9. Exemplos da topografia da seção transversal à trilha: (a) do MB do aço SAE 1010; (b) da ZAC de menor dureza da junta dissimilar;

(c) do MS da junta similar. Nas áreas circuladas ocorreu a dissolução de material adjacente à trilha, fora da região de desgaste.

Na Figura 8b, obtida para o MB do aço SAE 1010, não é possível distinguir na superfície as linhas relacionadas ao preparo das amostras antes dos ensaios ("marcas" da lixa \#1200), como é observado nas Figuras 8c e 8d referentes à ZAC da junta dissimilar e ao MS da junta similar, respectivamente. Esses resultados sugerem que toda a superfície do MB do aço SAE 1010 está coberta por um produto de corrosão, assim como na região de desgaste, que pode ter se formado parcialmente durante os ensaios, parcialmente após o desgaste - como citado anteriormente, após a etapa de desgaste os materiais ainda eram mantidos por mais 1 hora na solução, para observação dos valores de OCP. Na Figura 9a é mostrada a topografia de uma seção transversal à trilha da amostra ensaiada desse metal-base. Há uma grande variação na profundidade ao longo da região mostrada, superior às variações da ZAC da junta dissimilar, Figura 9b, e do MS da junta similar, Figura 9c.

Através da observação da Figura 8b e da Figura 9a, percebe-se que ocorreu dissolução de material nas bordas da trilha do MB do aço SAE 1010, fora dela, indicando que houve a formação de um par galvânico entre essa região e o restante do material que estava em solução. Adicionalmente, podem ser vistos alguns pontos onde houve corrosão por pites, inclusive dentro da trilha, fato que contribuiu para o volume removido total na área desgastada. A corrosão acentuada nas regiões adjacentes às trilhas, e também a corrosão mais localizada em determinadas regiões, foram observadas um estudo onde um aço carbono era desgastado em contato com diferentes soluções [14], e os autores atribuíram o fato à modificação da superfície devido ao processo de desgaste e à formação de microcélulas galvânicas entre ferrita e cementita. López-Ortega et al. [10] também observaram dissolução de material adjacente à trilha em ensaios de tribocorrosão em um aço de alta resistência baixa liga, porém quando eram aplicados potenciais anódicos. No presente trabalho, sugere-se que as alterações induzidas pelo processo de desgaste na região da trilha no MB do aço SAE 1010 podem ter levado à formação de um par galvânico, onde o material nas bordas da trilha atuou como o ânodo, dissolvendo-se. No entanto, essa dissolução acentuada não foi observada na amostra da ZAC de menor dureza da junta dissimilar, mostrada na Figura 8c, que se encontrava na chapa de aço SAE 1010. Nesta ZAC, o valor inicial de dureza era praticamente o mesmo do MB do aço, e a microestrutura era semelhante, com as diferenças essenciais de que a cementita da perlita na ZAC não estava disposta em lamelas, como estava no MB, e que estava mais distribuída entre os grãos de ferrita, como pode ser notado comparando-se a Figura $1 \mathrm{~b}$ e a Figura $6 \mathrm{~d}$. Espera-se que pelo processo de desgaste e tensões de contato envolvidas (Tabelas 3 e 5), ambas microestruturas tenham apresentado encruamento, mas essa alteração na morfologia e distribuição da cementita pode ter afetado a resposta em desgaste-corrosão na ZAC da junta dissimilar; com a ausência da formação de pites de corrosão e menor dissolução preferencial de material, é possível que o óxido formado tenha de certa forma protegido a trilha de desgaste, diminuindo o volume de material removido quando comparado ao $\mathrm{MB}$ do aço SAE 1010.

Na Figura 8c e na Figura 9b pode ser visualizada a indentação da esfera na região desgastada correspondente à ZAC da junta dissimilar, e percebe-se também que há uma região em ambos lados das bordas da trilha onde a altura (média) da superfície está mais baixa do que a restante, na região não desgastada, indicando a dissolução preferencial de material na área, porém de uma maneira bem menos pronunciada do que a observada no MB do aço SAE 1010. A consequência desses fatos foi 
o volume removido da região desgastada na ZAC do aço SAE 1010 ter sido na ordem de 6,5 vezes menor do que no MB deste aço. É interessante comentar que o mesmo padrão de comportamento mostrado na Figura 8c foi observado na amostra ensaiada do MS da junta dissimilar, porém com menor desgaste mecânico (menor profundidade de indentação da esfera na trilha), o que por sua vez resultou em um menor volume desgastado quando comparado à ZAC da junta dissimilar. Como pode ser visto na Figura $8 b$ e $8 c$, a esfera de alumina utilizada no ensaio realizado no MB do aço SAE 1010 ficou com algum material da trilha aderido na região vizinha à de desgaste, enquanto que era praticamente ausente na ZAC da junta dissimilar, correspondente a esse aço, sugerindo que o material transferido para a esfera na amostra do MB pode ter contribuído não apenas para o desgaste da esfera, mas também para o maior coeficiente de atrito resultante.

Comparada às demais condições estudadas, a esfera utilizada no MB do aço 1010 apresentou um valor de desgaste elevado, mas ainda inferior aos desgastes das esferas utilizadas nos ensaios do MS e da ZAC das juntas similares. Nessas duas últimas condições ensaiadas, o volume desgastado das esferas foi cerca de 2,5 vezes superior ao volume removido da região da trilha, como mostrado na Tabela 3.

A região desgastada do MS da junta similar pode ser visualizada na Figura 8d, e sua topografia na Figura 9c. Percebeu-se um acúmulo de produto de corrosão nas bordas das trilhas, indicando que ele foi removido do interior da trilha pela ação mecânica da esfera de alumina. Além disso, em proporções bem menores do que foi mostrado na Figura 8c, correspondente à ZAC de menor dureza da junta dissimilar, foi possível notar a indentação da esfera na região desgastada, e também uma pequena área adjacente à trilha onde parece ter havido a dissolução preferencial de material. Vale-se notar que esse foi o mesmo comportamento geral observado nos ensaios efetuados na ZAC de menor valor de dureza da junta similar.

Das condições estudadas que não apresentavam revestimento, o MB do aço Hardox 500 foi a condição ensaiada onde houve o menor volume removido da trilha, e a esfera utilizada nesse ensaio apresentou praticamente o mesmo valor de volume removido daquele da trilha, como mostra a Tabela 3. O valor do CoF ficou entre os maiores, em 0,42. As características da região ensaiada em tribocorrosão foram similares àquelas do MS da junta similar, mostrado na Figura 8d, porém não foi observada a região de dissolução preferencial adjacente à trilha. Além disso, a indentação da esfera na trilha de desgaste foi mais superficial. Apesar de as condições de ensaio serem diferentes, o comportamento superior do MB do aço Hardox está de acordo com o encontrado por Trausmuth et al. [13], que estudaram a tribocorrosão de aços de baixa liga com microestruturas ferrítico-perlítica e martensítica. Na presença de $\mathrm{CO}_{2}$, eles notaram que mesmo apresentando um maior valor de coeficiente de atrito, o aço com microestrutura martensítica desgastou menos. Eles atribuíram a menor taxa de desgaste do aço martensítico à maior homogeneidade da microestrutura em relação à ferrítico-perlítica, pois essa última apresentava corrosão preferencial da fase ferrítica e formava um filme de óxido mais poroso e com menor estabilidade mecânica do que aquele formado pela martensita. Assim, no presente estudo, supõe-se que a boa resistência à tribocorrosão apresentada pelo aço MB do Hardox deve-se à combinação da microestrutura martensítica e elevada dureza do material.

\section{Conclusões}

Neste trabalho, o comportamento em tribocorrosão de juntas soldadas utilizando um aço Hardox e um aço SAE 1010 foi avaliado através de ensaios de microdesgaste por deslizamento linear recíproco na presença de $0,05 \mathrm{M} \mathrm{de} \mathrm{NaCl}$.

Os resultados mostraram que nos ensaios efetuados no metal-base do aço Hardox com o revestimento de silicato de zinco, a solução de $\mathrm{NaCl}$ não chegou a entrar em contato com o substrato; houve desgaste de apenas parte do revestimento. No entanto, o desgaste da esfera de alumina foi elevado.

A microestrutura martensítica associada à elevada dureza foram provavelmente as responsáveis pela menor degradação nos ensaios de tribocorrosão no $\mathrm{MB}$ do aço Hardox sem o revestimento em comparação aos outros materiais ensaiados sem revestimento.

Exceto para o metal-base do aço Hardox, com ou sem revestimento, foi observado que a corrosão foi intensificada pelo desgaste. $O$ processo de desgaste alterou as características eletroquímicas dos materiais ensaiados. Houve a formação de um par galvânico, onde o material adjacente à borda da trilha, fora dela, comportou-se como o ânodo, dissolvendo. Essa dissolução foi mais intensa para o metal-base do aço SAE 1010, e nesse material também foram observados pites, inclusive dentro da trilha, o que contribui para um elevado valor de material removido no ensaio de tribocorrosão.

\section{Agradecimentos}

Os autores agradecem ao Laboratório de Pesquisa em Corrosão/UFRGS pelos ensaios de tribocorrosão efetuados, ao Laboratório de Análises Multiusuários/UFRGS pela utilização do interferômetro, e à Capes pelas bolsas de mestrado das alunas Thalita de Paula e Daniela Giarollo.

\section{Referências}

[1] American Society for Testing and Materials. ASTM G40-13. Standard terminology relating to wear and erosion. West Conshohocken: ASTM International; 2013. 
[2] Mathew MT, Pai PS, Pourzal R, Fischer A, Wimmer MA. Significance of tribocorrosion in biomedical applications: overview and current status. Advances in Tribology. 2009:1-12. http://dx.doi.org/10.1155/2009/250986.

[3] Celis J-P, Ponthiaux P, Wenger F. Tribo-corrosion of materials: interplay between chemical, electrochemical, and mechanical reactivity of surfaces. Wear. 2009;261(9):939-946. https://doi.org/10.1016/j.wear.2006.03.027.

[4] López-Ortega A, Bayón R, Arana JL, Arredondo A, Igartua A. influence of temperature on the corrosion and tribocorrosion behaviour of high-strength low-alloy steels used in offshore applications. Tribology International. 2018;121:341-352. http://dx.doi.org/10.1016/j.triboint.2018.01.049.

[5] Shibata K, Yamaguchi T, Hokkirigawa K. Tribological behavior of RH ceramics made from rice husk sliding against stainless steel, alumina, silicon carbide, and silicon nitride. Tribology International. 2014;73:187-194. http://dx.doi.org/10.1016/j.triboint.2014.01.021.

[6] Henry P, Takadoum J, Berçot P. Tribocorrosion of 316L stainless steel and TA6V4 alloy in $\mathrm{H}_{2} \mathrm{SO}_{4}$ media. Corrosion Science. 2009;51(6):1308-1314. http://dx.doi.org/10.1016/j.corsci.2009.03.015.

[7] Huttunen-Saarivirta E, Kilpi L, Hakala TJ, Carpen L, Ronkainen H. Tribocorrosion study of martensitic and austenitic stainless steels in $0.01 \mathrm{M} \mathrm{NaCl}$ solution. Tribology International. 2016;95:358-371. http://dx.doi.org/10.1016/j.triboint.2015.11.046.

[8] Manhabosco TM. Tribocorrosão da liga Ti6A14V, liga nitretada Ti6A14V, revestida por filmes Diamond-Like Carbon (DLC) e obtenção eletroquímica de filmes DL [dissertação de mestrado). Porto Alegre: Programa de Pós-Graduação em Engenharia de Minas, Metalúrgica e de Materiais, Universidade Federal do Rio Grande do Sul; 2009.

[9] Silva FN. Desgaste corrosivo-cavitativo-erosivo de um aço-carbono em meio aquoso com frações de sal ( $\mathrm{NaCl}$ ), $\mathrm{CO} 2$ e particulados sólidos (SiO2) [dissertação de mestrado). Natal: Programa de Pós-graduação em Engenharia Mecânica, Universidade Federal do Rio Grande do Norte; 2012.

[10] López A, Bayón R, Pagano F, Igartua A, Arredondo A, Arana JL, et al. Tribocorrosion behavior of mooring high strength low alloy steels in syntetic seawater. Wear. 2015;338-339:1-10. http://dx.doi.org/10.1016/j.wear.2015.05.004.

[11]Jiang J, Xie Y, Islam Md A, Stack M. The effect of dissolved oxygen in slurry on erosion-corrosion of En30B steel. Journal of Bio- and Tribo-Corrosion, 2017;3:45. http://dx.doi.org/10.1007/s40735-017-0105-0.

[12] Islam MA, Farhat ZN. The synergistic effect between erosion and corrosion of API pipeline in $\mathrm{CO}_{2}$ and saline medium. Tribology International. 2013;68:26-34. http://dx.doi.org/10.1016/j.triboint.2012.10.026.

[13] Trausmuth A, Rodríguez Ripoll M, Zehethofer G, Vogl T, Badisch E. Impact of corrosion on sliding wear properties of low-alloyed carbon steel. Wear. 2015;328-329:338-347. http://dx.doi.org/10.1016/j.wear.2015.02.061.

[14] Liu Y, Mol JMC, Janssen GCAM. Corrosion reduces wet abrasive wear of structural steel. Scripta Materialia. 2015;107:92-95. http://dx.doi.org/10.1016/j.scriptamat.2015.05.028.

[15] Hacisalihoğlu I, Yildiz F, Çelik A. Tribocorrosion behavior of plasma nitrited Hardox steels in NaCl solution. Tribology International. 2018;120:434-445. http://dx.doi.org/10.1016/j.triboint.2018.01.023.

[16] SSAB Oxelösund. SSAB OX Tech Support \#25. Shop primers used by SSAB Oxelösund. [acesso em 13 nov. 2019]. Disponível em: http://www.highstrengthplates.com/images/pdfs/TS_ssab_plate_UK.pdf

[17] Australasian Corrosion Association Inc. Inorganic zinc coatings - history, chemistry, properties, applications and alternatives. 2nd ed. Preston: ACA; 2013. 271 p.

[18] Parashar G, Srivastava D, Kumar P. Ethyl silicate binders for high performance coatings. Progress in Organic Coatings. 2001;42(1-2):1-14. http://dx.doi.org/10.1016/S0300-9440(01)00128-X.

[19] Stragliotto BV, Machado IG. Tratamento térmico por indução eletromagnética em juntas soldadas com o processo de arco submerso. In: Anais do XXVIII Salão de Iniciação Científica da Universidade Federal do Rio Grande do Sul; Porto Alegre. Porto Alegre: UFRGS; 2016.

[20] Landolt D. Corrosion and surface chemistry of metals. Lausanne: EFPL Press; 2007. 400 p. http://dx.doi.org/10.1201/9781439807880.

[21] Accuratus. Aluminum oxide, Al2O3 ceramic properties [acesso em 1 nov. 2019]. Disponível em: http://www.accuratus.com/alumox.html

[22] Ramos LB, Simoni L, Mielczarski RG, Vega MRO, Schroeder RM, Malfatti CF. Tribocorrosion and electrochemical behavior of DIN 1.4110 martensitic stainless steels after cryogenic heat treatment. Materials Research. 2017;20(2):460-468. http://dx.doi.org/10.1590/19805373-mr-2016-0341.

[23] Sergejev F, Petrov M. Assessment of residual stresses in steels and carbides composites by load and depth sensing indentation with spherical indenter. Estonian Journal of Engineering. 2012;18(3):259-269. http://dx.doi.org/10.3176/eng.2012.3.11.

[24] MakeltFrom.com. SAE-AISI 1010 (S10C, G10100) Carbon Steel. [acesso em 1 nov. 2019]. Disponível em: http://www.makeitfrom.com/material-properties/SAE-AISI-1010-S10C-G10100-Carbon-Steel

[25] Azzi M, Paquette M, Szpunar JA, Klemberg-Sapieha JE, Martinu L. Tribocorrosion behavior of DLC-coated 316L stainless steel. Wear. 2009;267(5-8):860-866. http://dx.doi.org/10.1016/j.wear.2009.02.006. 
[26]American Society for Testing and Materials. ASTM G133-2005. Standard test method for linearly reciprocating ball-on-flat sliding wear. West Conshohocken: ASTM International; 2005.

[27] Murkute P, Ramkumar J, Choudhary S, Mondal K. Effect of alternate corrosion and wear on the overall degradation of a dual phase and a mild steel. Wear. 2016;368-369:368-378. http://dx.doi.org/10.1016/j.wear.2016.09.027.

[28] Noh HJ, Jang H. Friction instability induced by iron and iron oxides on friction material surface. Wear. 2018;400-401:93-99. http://dx.doi.org/10.1016/j.wear.2017.12.025.

[29] Wu H, Li Y, Lu Y, Li Z, Cheng X, Hasan M, et al. Influences of load and microstructure on tribocorrosion behaviour of high strength hull steel in saline solution. Tribology Letters. 2019;67(124):12p. http://dx.doi.org/10.1007/s11249-019-1237-9.

[30] Kogut L, Etsion I. A semi-analytical solution for the sliding inception of a spherical contact. ASME Journal of Tribology. 2003;125(3):499506. http://dx.doi.org/10.1115/1.1538190.

[31] Lin LP, Lin JF. An elastoplastic microasperity contact model for metallic materials. ASME Journal of Tribology. 2005;127(3):666-672. http://dx.doi.org/10.1115/1.1843830.

[32] Pintaude, G. Analysis of spherical contact models for differential hardness as a function of Poisson's ratio. ASME Journal of Tribology, 2015;137(4):044502. 